\title{
The Art of Community ... What Principles and Practices do RTLB need to Develop an Effective Community of Practice?
}

\author{
Ivanka Soljan and Wendy Holley-Boen
}

\begin{abstract}
Communities of Practice (COP) have been used in schools and other educational institutions as a way of growing knowledge and managing change. This article centres on one professional inquiry with a group of Resource Teachers: Learning and Behaviour (RTLB) and using a strengths-based approach, explores the elements that increased the effectiveness of COP. Through semi-structured interviews, the participants discussed the elements of COP they had previously found to be effective and what had made them so. These conversations with RTLB highlighted that having a shared understanding across all stakeholders regarding the definition, purpose and intent of their COP was important to ensure their usefulness. Autonomy, flexibility, engagement of both the head and the heart, focusing on work, whakawhanaungatanga and ako were also found to be key components in ensuring the smooth running and effectiveness of the COP.
\end{abstract}

\section{Research paper}

\section{Keywords:}

change, community of practice, professional inquiry, RTLB, strengths-based approach

\section{INTRODUCTION}

Change is a common dimension of the current educational climate. Whether it is teachers changing practice, schools changing structures, or institutions having to deal with wider policy changes, organisations seem to have to adapt to, or incorporate, a barrage of change with fluidity and timeliness.

It is now recognised that change is not a simplistic or linear process, but a dynamic one that occurs in unpredictable and complex ways (Coppieters, 2005). Some authors believe that for schools to readily embrace an ever-changing environment there has to be an emphasis on learning; where growing and assimilating new knowledge are a natural part of the working culture. As the acceptance of new ideas are fostered, change then becomes a natural part of that context (Fullan, 2008; Louis, 1994; Senge, 2012; Steenekamp, Botha \&
Moloi, 2012). In other words, change and learning are intertwined: as we learn, we change.

One way to foster learning and change is through COP. These communities create a climate by which people socially construct meaning and knowledge through dynamic dialogue and sharing of ideas. Creating effective communities could be viewed as an art form rather than a science. It takes time to forge an environment for people to communicate and collaborate positively. It is not about having an exact recipe or formula, but more like a painting in which an artist has to imagine an overall concept, as well as use an array of techniques on the fine details to make the picture come alive. Just as each artist, or in the arena of communities, several artists, have a unique approach to their work, so do COP which are propelled by context and purpose. This research explores the common principles and practices of COP and focuses on one particular profession within education: Resource Teachers: Learning and Behaviour (RTLB). In essence, the research considers the artistry of communities RTLB are involved in.

RTLB are a specialist group of teachers working primarily with schools and teachers (Years 1 - 10) in New Zealand to grow the engagement and achievement of students with diverse educational needs. There are 40 geographically-defined groups (called clusters) across the country employing approximately 915 RTLB (Ministry of Education, 2015). The RTLB role works with school-wide systems and with teachers, focusing on individuals or small groups of students within the classroom setting. RTLB use an ecological, collaborative approach underpinned by a strengths-based perspective. The nature of RTLB work is multi-faceted and requires a breadth and depth of knowledge for a range of issues and contexts.

RTLB often encounter highly-complex situations, which makes them ideal candidates for a Community of Practice approach. The collaborative nature of the RTLB role makes for a logical progression to community-styled learning and professional development. Whether or not they identify them as such, most RTLB are already involved in numerous and varied COP. 
This paper will give a definition and overview of the structure of COP and provide a review of recent literature. It then hones in on COP particular to RTLB. Using findings from semi-structured interviews, this inquiry draws out key themes around what principles and practices make COP effective for RTLB.

\section{What are Communities of Practice?}

Communities of Practice (CoP) are groups of people who share a concern, a set of problems or a passion about a topic, and who deepen their knowledge and expertise in this area by interacting on an ongoing basis (Wenger, McDermott \& Snyder, 2002, p. 4). COP treat teachers as active learners who interpret new knowledge and reconstruct teaching practices within their contextual boundaries (Mak \& Pun, 2015). By design, COP vary considerably; small or large, within or across organisations, spontaneous or intentional; however they all share the three core elements of domain, community and practice (Wenger, 1999). The domain frames the body of knowledge and set of issues to be considered, focuses the discussion and creates a sense of common identity and meaning. The community creates the social fabric for learning and is premised on mutual trust and respect. It encourages dynamic discourse that asks difficult questions and listens to one another. Community is an important element in COP as "learning is a matter of belonging as well as an intellectual process, involving the heart as well as the head" (Wenger et al., 2002, p. 29). Practice is a shared repertoire of tools, experiences, stories, language and documents that enables the community to move forward with relative efficiency. All three domains are deepened and developed over time and require sustained interaction.

The activities that occur within COP are as varied as the participants. Activities can include problemsolving, discussing experimental ideas, mapping knowledge and identifying gaps, and offering support and encouragement for its members (Wenger \& Trayner, n.d.). Participants can range from novices to experts, with some centrally involved and others on the periphery. All members are seen as valuable; those not actively contributing in one group may still be gaining and applying insights to their work and within other communities (Wenger et al., 2002).

COP can fulfil a number of different purposes with respect to the creation, accumulation and diffusion of knowledge in an organisation (Mittendorff et al., 2006). As knowledge is situated and socially constructed within an organisational context, COP are an active vehicle for that knowledge. The shared understanding within COP enable organisations to create, recreate and preserve knowledge in a dynamic way, where both tacit and explicit understandings are explored. Through this exploration, members negotiate their identity within the community and develop a sense of belonging (Wenger, 1999). The purposes of COP are in and of themselves dynamic, flowing between personal growth and changes to the wider organisational environment. CoP, therefore, are valued differently depending on where a person is situated within the community and the organisation.

\section{LITERATURE REVIEW}

Do Communities of Practice Really Change Teacher Behaviour?

Due to the dynamic and self-directed nature of CoP, effectiveness is difficult to measure. An ideal community has its own purpose and trajectory that evolves around the changing needs of the organisation and its participants (Wenger et al., 2002). Communities need to create events, activities and relationships that help values emerge rather than predetermining an outcome; thus a focus on value rather than outcome is key (Wenger et al., 2002). The value of a community, therefore, develops and transforms with the ebb and flow of the people and their practices, and is best determined by the members themselves.

There are, however, some qualitative studies that have attempted to record the COP effectiveness. Cuddapah and Clayton (2011) noted that novice teachers had a high level of participation in a community of practice, and suggested that this participation led these new teachers to see themselves as competent and agentic professionals. Another study identified that teachers co-construct their efficacy beliefs within a community of practice; while it cannot be said that collaboration caused strong efficacy beliefs, the nature of the collegial practices enabled teachers to collectively co-construct and reinforce those beliefs (Takahashi, 2011). As positive self-efficacy motivates and promotes teacher agency, reinforcement of that agency in a collegial setting suggests that COP can be a part of the change process for classroom practice. Looking at social justice issues, Flores (2007) emphasised that COP are a good way to support teachers situated learning in creating transformative practice. In her study of four beginning teachers, Flores identified COP as an essential tool not only for challenging cultural inequities but also for sustaining teachers' sense of hope when facing other teachers' negative attitudes towards students. Similarly, a study of second-language teachers in Hong Kong highlighted teachers' adaptations to their classroom strategies through engagement with a vibrant and supportive community (Mak \& Pun, 2015). These studies highlight the variety of ways effectiveness of COP can be measured, from personal change to more external adaptations of practice.

Not all literature endorses COP as a tool to promote change. Examining how three COP stimulated learning, Mittendorff et al. (2006) found that not all groups 
function as COP or have the potential characteristics for collective learning. Even when tight relationships were formed, group dynamics, such as 'open mindedness to change' hindered the learning process. Horn and Little (2010) found that not all group conversation led to authentic change. Those whose conversations tended to move 'away' from teaching were less-likely to transfer knowledge to their own classroom practices. For instance, primarily 'show and tell' dialogue did not involve collaborative problem-solving and tended to focus more on administrative demands. Effective group conversation moved between the specifics and generalisation of teaching, enabling participants to emotionally link with and normalise an issue. They were able to "conversationally construct general frameworks for thinking about teaching problems, providing durable tools for their work" (Horn \& Little, 2010, p. 202). These findings may indicate that the communities studied, whilst labelled as a COP, were not technically functioning as such, as they were not effectively meeting the three criteria of domain, community and practice.

\section{What Makes a Community Effective?}

A theme throughout the literature was that communities with perceived value or effectiveness tended to include certain principles and practices across the domain, community and practice.

\section{Domain: Shared Vision}

Shared vision has been highlighted as one of the most important characteristics of successful collaboration and a core component of learning communities as it links individual knowledge bases to a shared purpose (Robertson, 2007; Wilson \& Pirrie, 2000). If members don't feel personally connected to the group's area of expertise and interest once it has been defined, they won't fully commit themselves to the work of the community (Wenger \& Snyder, 2000). Shared visions need concentrated discussion and time to be developed and refined; by doing this the opportunities within a community remain relevant to its participants (Akerson, Cullen \& Hanson, 2009; Edwards, 2012; Richmond \& Manokore, 2011; Robertson, 2007; Trotman, 2009). Issues can arise in groups if a shared vision is ill-defined or too restrictive; members need clarity regarding the aims of the group, and a vision not so tightly bound that it doesn't provide enough flexibility to meet personal goals or access a variety of learning opportunities (Fuller, Hodkinson, Hodkinson, \& Unwin, 2005). Some authors caution against developing a shared vision. They note that groups may become too cohesive in their vision, where there is little chance for diversity of thought or the questioning of tacit power structures or poor practices. These approaches may inhibit the possibility of creativity and change (Printy, 2008; Watson, 2014). While having a shared domain and vision are essential to growing a community of practice, it appears there must be some consideration as to how the vision is arrived at by its members.

\section{Community: Voluntary Membership and Different Levels of Participation}

Membership within a community is self-selected and a critical factor of a CoP. People tend to know when and if they should join and whether a COP is likely to benefit them in some way (Wenger \& Snyder, 2000). Participants are more likely to be fully engaged and committed, and therefore collaborative work can deepen more quickly (Mak \& Pun, 2015; McLaughlin \& Talbert, 2006). Voluntary membership also guards against 'contrived collegiality', which is derived from hierarchical approaches to learning communities and presses participants to collaborate on issues that are not necessarily related to their needs or context (Rawlins, Ashton, Carusi \& Lewis, 2014). Some authors highlighted disadvantages with voluntary membership: Snow-Gerono (2005) suggested that when teachers selfselect their own learning communities, they may only choose like-minded participants and leave oppositional voices on the outside. The concern is, there becomes a lack of diversity within the group that stifles dynamic discussion and may leave tacit beliefs unchallenged. This 'groupthink' discourages reflection on deficit thinking and may endorse ineffective practices (Cuddapah \& Clayton, 2011).

One way of managing this difficulty is to allow for different levels of participation (Wenger, 1999). This does not only pertain to peripheral and active members, but also having a combination of expertise and novices within the group. Cuddapah and Clayton (2011) recognised that an all-novice learning culture can be woefully lacking in knowledge. They suggest that integrating teachers with a variety of expertise can often provide some of the best support for new teacher learning. Fuller et al. (2005) noted that through their engagement with novices, experienced workers can also learn, as all people bring a range of knowledgeable skills that they are capable of sharing. In a New Zealand context, this reflects the concept of 'ako' where learning and teaching are not opposing concepts but occur simultaneously. Participants, therefore, embody both the role of learner and teacher while engaging in community experiences and discourses.

\section{Community: Leadership within Communities of Practice}

The organic, spontaneous and collaborative nature of COP causes questions to arise about whether a member should take a leadership role. COP reflect the social relations of its members and on the basis of these relations, some individuals may function as informal 
leaders who keep the communities purpose at its centre and who help to shape social relationships among members to facilitate learning (Printy, 2008, p.193). It is argued that a distributed style of leadership is more effective within COP where leadership is fluid in nature, and people step into roles of responsibility around their strengths and interests as need arises (Crafton \& Kaiser, 2011; Robertson, 2007). This style of leadership creates a sense of interdependence within the community, where people are accountable to and reliant on one another to achieve their shared goals. Wenger et al. (2002) suggested that groups should have a facilitator. This person tends to coordinate activities, has a strong connection to the domain of the COP and is highly motivated to keep the group active. The facilitator may be well-versed in the field, but are not experts: that role acts to create networks, not provide answers.

It should also be noted here that COP do not operate in isolation, and that support from wider organisational structures is important and necessary. Schools and organisations that provide COP with infrastructure, time and resource, as well as valuing knowledge-creation, help to ensure that COP are effective (Mittendorff et al., 2006; Wenger \& Snyder, 2000). These organisations can also help to mitigate political and bureaucratic demands on communities. It has been observed that organisations that cultivate learning communities and then give participants autonomy around the direction and processes of the community itself, benefit from innovative ideas and motivated participants (Pink, 2009; Vescio, Ross \& Adams, 2008; Wenger \& Snyder, 2000).

\section{Community: Group Dynamics}

In any collaborative venture, the dynamics of the group plays a role in how the community functions. Much of the literature highlights mutual trust, openness, a safe environment and commitment as essential elements in a community (Akerson et al., 2009; Bianchini \& Cavazos, 2007; Mak \& Pun, 2015; Mittendorff et al., 2006; Robertson, 2007; Snow-Gerono, 2005). The literature also acknowledges that as communities begin to grow together and formulate their domain, community and practice, they will have times of conflict, uncertainty and power struggles which can reduce the sense of fraternity within the group. These authors note that open dialogue, listening and time is essential to ensure that participants can understand the perspectives of others before they can begin to collaborate with effectiveness (Mak \& Pun, 2015; Mittendorff et al., 2006; Robertson, 2007; SnowGerono, 2005).

\section{Practice: Dialogue}

Dialogue is the crux of any learning community. All activities and experiences are centred around language and the art of discussion. Horn and Little's (2010) research found that the style of dialogue had a direct impact on authentic change in teacher practice. The two communities they studied, both with similar domains and contexts, had varied conversational routines. The group who relied on shared language and frames of reference that were focused on their specific domain, appeared to have more productive conversations and therefore an increased impact on teacher practice. Akerson et al. (2009) highlighted that 'good conversations' should be facilitated within communities as this fosters perspective taking, helps develop personal and professional authority, revives hope, and reaffirms ideals. These conversations can also support the articulation of implicit theories and beliefs which generate a social consciousness and, in turn, fosters the ability to act, thus affecting teacher practice (Jenlink \& Jenlink, 2008; Snow-Gerono, 2005; Timperley, 2007).

\section{Practice: Conflict in Conversations}

Pane (2010) observed that "learning occurs through the transformative potential of negotiated, often uncomfortable interactions among communities of practice" (p. 93). In any diverse community competing values and ideas will arise, and the ability to embrace and learn from these conflicts is an essential component of a CoP. Snow-Gerono (2005) called this 'dissensus', where "teachers may disagree on and critique aspects of teaching and learning in a manner that acknowledges the tensions inherent in education and ideological frameworks and embraces problem-posing as a means for professional development" (p. 251). Teachers are likely to feel dissonance as they expose their practice to others, which can arouse fear and tension. It is suggested that relationships built on trust, honest interactions, selfrevelation and sensitivity are an antidote to such tensions (Dooner, Mandzuk \& Clifton, 2008; Mak \& Pun, 2015).

This literature review indicates that COP have the potential to influence and change teachers' practice if they embody some of the principles discussed above. What is notable is that most of the literature sourced for this review is generated internationally and focused on classroom teachers or higher learning institutions. This research project has been designed to focus on two areas that are not so prominent in the literature: specialist teachers (RTLB) within a New Zealand context. It aims to answer the question: What principles and practices underpin an effective COP for RTLB?

\section{METHOD}

This research took place within one RTLB cluster. It is an ethnically diverse urban setting and contains approximately 35 RTLB who service about 70 schools. These schools vary from: small to large in student numbers, low to high decile, and range across the spectrum of primary, intermediate and secondary 
schools as well as Kura Kaupapa (Māori immersion school). Six RTLB took part in the research and were purposively selected so as to get a diverse representation of people from across the cluster. Three of the RLTB were approached directly as they fitted a 'niche' section e.g. Māori or management. The rest of the cluster was divided into two groups; experienced (working in the cluster for four years or more) and novice (working in the cluster for less than four years but more than one year). Any RTLB who had been in the role for less than a year was excluded from this study because they may not have enough experience to draw on when discussing their involvement in COP as RTLB. The remaining three people were randomly selected from these two groups. The final group consisted of three experienced RTLB and two novice RTLB, as well as one manager. Of those six, one RTLB was male and of Pacific Island origin and another identified as Māori. Informed consent was collected from each RTLB prior to conducting the research. In terms of ethical considerations, to protect the confidentiality of the participants, no names or other identifying features were used in the research. The participants had the right to withdraw their consent at anytime.

Semi-structured interviews were used as the data collection method, and the questions were designed to focus on one COP experience that RTLB perceived as 'successful'. This process was used to examine participant comments and gain insight and depth of opinion that other data sources might not afford. All participants were invited to choose the location of the interview; koha (gifts) were provided in the form of food and coffee, and the interviews were conducted informally. For the most part, the participants received the questions prior to the interview to provide time for them to reflect on a community they might like to explore (see Appendix A). The aim was to give the participant a strong voice in the interview situation and centre the conversation on their COP story (Menter, 2011).

A strengths-based or appreciative approach was used to guide the design of this interview, as it allowed me to identify what was good, and what energised and motivated people (Cooperrider, 2012). This approach focused on what gave 'life' to a living system, to hone in on what was most effective and then to build on that knowledge to grow and enhance the system (Cooperrider \& Whitney, n.d.). I chose to use a strengths-based approach for three reasons. Firstly, this notion is one of the seven principles of practice for RTLB (Ministry of Education, n.d.) and is an important underpinning for RTLB work. Secondly, I wanted to ensure that the interviews upheld the integrity and skills of the RTLB. Focusing on what works well asks RTLB to look at their work in a positive and creative way, and enables them to provide the building blocks for further development. Finally, working collaboratively may not always be a positive experience for people. As my interview questions focus on personal experiences of $\mathrm{CoP}$, it had the potential to highlight times that may have caused some anxiety and stress. By using a strengthsbased approach the aim was to reduce the focus on difficulties and to potentially divert unnecessary stress for participants.

Once the interviews were conducted, the information was coded using concepts from the COP literature as well as additional themes that consistently arose across participants. These codes were then organised into overarching categories and became the key motifs for the findings. Throughout the analysis process I discussed the findings with several educational researchers as a way of confirming the validity of my conclusions as well as revisiting concepts with the actual participants to ensure that I captured their ideas correctly (Takahashi, 2011). $\mathrm{I}$ also engaged in a research-focused COP and gleaned valuable insights as to this process from my peers.

\section{FINDINGS}

The principles and practices that RTLB considered to enhance their COP fell under six general themes: engaging the head and the heart, directly work-related, autonomy and flexibility, whakawhanaungatanga, ako, and practicalities.

\section{Engaging the head and the heart}

One of the key findings that came from the conversations with RTLB was their high levels of engagement with the COP process. All interviewees were motivated to attend their communities and prioritised them, despite their sometimes-overloaded schedules. While a variety of reasons contributed to this motivation, it appeared that two key areas had to be established to foster engagement. The group had to have a clear and defined purpose for existing and the RTLB had to have a strong interest in what was happening. This finding could be called 'engaging the head and the heart'.

Having a purpose corresponds with Wenger's (1999) concept of the domain, and reflects discussion in the literature on shared vision. The RTLB knew why they were meeting and what to expect from their colleagues.

You know often it's ... you might get presented with 10, 12 priorities or 'blah, blah blah'... I guess it's nailing that down to a top 3 or 4 and ranking them, you know, here's our 1, 2, 3 or 4 and agreeing on those, so that's your common starting point (Participant 3, personal communications, July, 2015)

Other groups' visions were less structured, but these RTLB acknowledged that they needed to be clear about 
why they were meeting. While Wenger, McDermott and Snyder (2000) suggested that this type of knowledge could be implicitly known, it appeared that for the RTLB having an explicit idea of why they were meeting appeared to hone in and focus their community, which made the time spent in COP valuable. This focus also meant that the discussions in the community were extremely purposeful. Most of the RTLB highlighted that the sessions concentrated on their current work and were specific to their needs, however this was not narrow or tied to a particular goal. Developing a clear vision in communities is recognised in literature but having scope within that purpose is essential so that the group can meet the personalised needs and expectations of the members with flexibility and creativity (Akerson et al., 2009; Fuller et al., 2005).

In terms of engaging the heart, it appeared that for half the participants their COP was centred around an area of interest or 'passion', for example; having a cultural or secondary focus.

There's nothing like being with people, in a community where everyone is really excited about the same thing (Participant 6, personal communication, 4 August, 2015).

Two other RLTB commented that the communities challenged their thinking and enabled them to have lively discourse around current issues or topics. Their 'interest' , therefore, was not a particular subject, rather the creation of dynamic conversation and exposure to new ideas. Either way, RTLB were motivated by a sense of enthusiasm around their work. In essence, this meant that COP served a more holistic purpose; not only did it feed the mind but also engaged those nebulous values and passions that are part of people's identity.

\section{Directly work-related}

All RTLB were able to identify a correlation between their COP and a significant change in their practice. These changes included things such as taking away a tangible assessment, strategy or intervention to use in casework, a deeper conviction of the theory and purpose of their practice, or a transformed understanding of a difficult situation through the exposure to multiple viewpoints from the community. The following comments highlight the reflective and practical workrelated nature of the $\mathrm{CoP}$.

Because I was talking to other people about what they were doing, and they were reflecting and that meant we were getting clarification out of that, it made me much more reflective on my own practice. It made me question my practice at times (...) and it increased my skill and my awareness, I had more information to draw from (Participant 1, personal communication, July, 2015)
I went away with something tangible that I could work with (Participant 6, personal communication, July 2015).

Five out of the six RTLB identified that these experiences had a direct influence on their work at the 'chalk face'. That is, the teachers, students and schools they were working with had benefited from their involvement in a CoP. They also recognised that COP went beyond their daily work; it helped to develop and deepen relationships and began to build a networked support system both within the cluster and created links to the wider community e.g. psychologists, MOE, other RTLB clusters.

The RLTB manager was in the process of gathering outcomes information from the current communities running in the cluster and therefore felt she was unable to comment on the potential success of those CoP. She did, however, highlight the need for any community of practice to be able to demonstrate a visible and valuable influence on schools as the following excerpt shows.

What we do internally in the cluster has to be for the common good of the schools (...) there is a difference between exploring for own personal benefit and a community that provides a more valid and useful service for schools (Participant 5, personal communication, 4 August, 2015).

It appears that a key principle required for effective COP is that the focus and content is directly related to RTLB work. This concept, however, was not as straightforward as it initially appeared. There were some differences regarding the definition of 'directly related to work' between RTLB and management. It appears that RTLB saw 'work-related' as their changes in their personal practice; shifts in underlying beliefs, trying a new resource or strategy, or going to a meeting with a new perspective and empathy for the participants. On the other hand, management needed to see 'work-related'. They needed evidence to show that the communities added value by observing a direct impact on schools and teachers. This distinction reflects the differences between the communities described by RTLB and management; open-ended versus project-oriented. This divergence highlights a conflict as to the definition of CoP, and has the potential to undermine its effectiveness, as expectations are not met.

\section{Autonomy and Flexibility}

Autonomy and flexibility were words spoken frequently by RTLB in our conversations. They identified that COP were more effective when groups determined their own agenda. It appeared that autonomy and flexibility were essential so that RTLB could decide on what was important for them, as well as affording them the capability to evolve as the needs arose. 
RTLB in four out of the six communities joined voluntarily, which indicates a sense of autonomy, and strongly aligns with the literature regarding COP design (Wenger et al., 2002). RTLB who chose to join their communities considered it was a beneficial use of time.

I always self-reflect so I would self-reflect on what I'd learned in the CoP\} and whether it was valuable, and I think if I'd self reflected and I wasn't actually learning new things or gaining I would have withdrawn (Participant 2, personal communication, 24 July, 2015).

Having autonomy and flexibility had the potential to clash with managerial expectations regarding time and content, as sometimes organisational frameworks were imposed on CoP. These frameworks occurred in such forms as having to conform to particular topics, following a certain system of record-keeping or demonstrating adherence to measurement outcomes. The RTLB manager stressed the importance of having a precise and purposeful focus for COP as a way of ensuring that groups had a clear pathway for development. Also noted was pressure for management to justify RTLB work in light of external expectations, such as Ministry of Education or media. RTLB felt they needed flexibility and autonomy to make decisions around what work they engage with and how they engage with it. One RTLB likened this dilemma to a conflict between time and wã (the Māori concept of time). This meant that western notions of time, which are quite fixed and established, clashed with more nebulous or fluid Māori beliefs. In essence, this was about trying to balance the need for autonomy to make decisions on the space, time and place of COP with the organisational frameworks that RTLB worked under.

These opposing viewpoints perhaps highlight a division in the expectations of what COP should deliver. RTLB appear to want the opportunity to create and grow their knowledge-base according to their needs and agendas, while the management want tangible outcomes, something that can be seen and shared. Both approaches hold value, however, asking a group to produce a final outcome breaches the 'pure' definition of what a community of practice is. The group then becomes something of a project team rather than a CoP, where they have to accomplish a task rather than generate, expand and exchange knowledge (Wenger et al., 2002). There is also a danger of rigidity, where groups become impervious to change as the processes are too tightly defined (Wenger et al., 2002). Understanding this mismatch regarding the function of group learning and ensuring that the greater purpose is clearly defined is important as unmet expectations can lead to dissatisfaction and reduced engagement in the work of RTLB. This tension was highlighted by one RTLB when she was reflecting on a community that wasn't working so well:
We were asked to set a goal, I think that created some stuckness, or whatever the word is, it was too focused and not enough flexibility and I think that stopped our voices somehow (...) and then (stopped) it to sort of flow (Participant 6, personal communication, 4 August, 2015).

Generally speaking, it appears that having autonomy and flexibility to determine the nature, focus and processes of COP increased RTLB's sense of professionalism, motivation and engagement. This need for autonomy reinforces the call for a clear and unified definition of what a COP is, to balance the expectations between management and RTLB.

\section{Whakawhanaungatanga}

Whakawhanaungatanga literally means, "to birth the collective" (Pa Tate, 1993 as cited in Pihama et al., 2004). This concept was a common thread throughout all of the interviews and emphasised the significance of building effective relationships. RTLB commented on the importance of valuing one another, respect, safety and trust within their groups and recognised that it was this that enabled them to share the 'good, bad and the ugly' of their practice.

There's gotta be trust and safety (...) cause I need to feel safe if I'm sharing and I need to feel safe ... if I'm sharing knowledge but also if I'm saying actually I haven't a clue about ... whatever (Participant 6, personal communication, 4 August, 2015).

There was also mention of the attitude that people brought to their communities, such as open-mindedness, and a willingness to be vulnerable and to listen.

People were very honest and I think that that's where the respect really came too. I was very happy to admit a shortfall or not knowing something, I was quite happy to say I've got this (and) I don't know what to do, or you know... it was always wonderful to say ... what would you do in this situation or what do you see? (Participant 1, personal communication, 23 July, 2015).

These comments suggest that RTLB come to their community with a learning mind-set and are receptive to new ideas. This finding reflects the research of Mittendorff's et al. (2006) showing that 'open mindedness to change' is a vital quality to have to increase the effectiveness of CoP.

From the RTLB conversations it appeared that much of these effective group processes were deliberately fostered. For example, three groups intentionally included an informal 'catch-up and chat' within each session over coffee and kai (food). One RTLB noted that due to time pressures their group stayed highly focused in their time allocation; however, they would 
have "informal chats at other times, like going out for coffee" (Participant 3, personal communication, 27 July, 2015). The RTLB realised the value and importance of relationships when learning and working together and intuitively cultivated those relationships to build trust and respect and ensure positive collaboration. This notion of relationship is congruent with COP literature, which acknowledges that safety, trust and openness are essential elements of COP (Akerson et al., 2009; Bianchini \& Cavazos, 2007; Mak \& Pun, 2015; Mittendorff et al., 2006; Robertson, 2007; SnowGerono, 2005). Creating positive relationships in COP also highlights the necessity of open dialogue, listening to one another and empathy as key methods of fostering positive communications (Mak \& Pun, 2015; Mittendorff et al., 2006; Robertson, 2007; Snow-Gerono, 2005). It appears that these RTLB possessed the will and the skill to collaborate effectively, and this contributed to a worthwhile COP experience.

Interestingly, in today's technology-focused world, all communities mentioned in the interviews met face to face (kanohi ki te kanohi), which was used as a way to encourage a deeper form of connection and community. This need for connection was noted in the following excerpt:

It's about being in the moment ... are we comfortable together, are we sharing, are we

listening... (Participant 6, personal communication, 4 August, 2015).

Complementing this ideal were the number of comments made regarding the environment that people met in. The environments were purposefully selected to meet the needs of the group.

One group met in someone's home as it was comfortable, held no interruptions and ensured people's confidentiality and safety. Another group met in a professional space with a large board table and a number of resources at arms reach. The 'place' of meeting held significance as it contributed to the comfort, safety and needs of the group, which therefore enhanced the connections and trust within the group.

\section{Ako}

The concept of ako is grounded in the notion of reciprocity and recognises that the learning and teaching are not separate entities (Ministry of Education, n.d.). Within COP this means that participants are learning and sharing at the same time. The RTLB all reflected this principle within their communities. Ako was deepened through the acknowledgement of different backgrounds and perspectives. The differing perspectives were pertinent in both COP that included only RTLB and communities involving a mixture of professionals e.g. educational psychologists, Ministry of Education or
Kuia (elders). The group discussions were regarded as richer by all RTLB due to the variety of experiences and expertise people brought to the group.

Because there was about 7 of us we all had a lot to contribute and we all had different strengths. So that I guess was the beauty of it, you were coming from your place of skill and expertise and throwing that in the mix and we were all different, yeah, yeah, it was neat (Participant 6, personal communication, 4 August, 2015).

The group had the ability to bring in different perspectives and ability to ask probing questions (Participant 5, personal communication, 3 August, 2008).

A natural outflow of practising ako was the effect that it had on the dialogue within the CoP. RTLB commented that the conversations were extremely work-focused and mainly consisted of professional discussion, questioning, problem-solving and offering solutions. The RTLB also noted that there was little or no interpersonal conflict within the groups. It may be that recognising all participants are of value increased the sense of respect between members. All parties were afforded air time with a sense that no one person had all the answers and no individual had one 'right' answer, as the following quote highlights.

\section{Just because I'm P.I. (from the Pacific Islands) doesn't make me the expert, and just because colleagues are Māori, doesn't make them the expert, and I'm willing to bet they don't see themselves in that way anyway. I think being P.I. and male in my cluster makes me very different, with a different lens to things (Participant 3, personal communication, 27 July, 2015).}

While all RTLB communities practised ako, there was always one person who took the lead in coordinating the group. This person appeared to take responsibility for communications, sharing agendas or minutes (if these were used), liaising with group members, and ensuring all parties were informed of relevant information. This coordinator reflected Wenger, McDermott and Snyder's (2002) concept of 'facilitator' as they had an equal part in the dialogue of the group, were not seen as an expert, and took a motivating role in ensuring the group met and ran smoothly.

\section{DISCUSSION}

As not all findings can be discussed, the following centres on a few of the key aspects of this inquiry, drawing on one main idea from each theme.

The feedback from this group of RTLB shows that COP can have a positive impact on their practice. The effectiveness of these communities is increased when 
all stakeholders have a clear and united understanding of the definition, function and purpose of CoP. When referring to learning community as a COP it is important to develop an accurate, shared and evolving understanding of what that means to save confusion, unmet expectations and ultimately demotivation or lack of engagement. The findings showed that the different understandings between management and RTLB caused disruption to this process. While other literature has noted the importance of creating organisational structures that validate COP (Vescio et al., 2008; Wenger \& Snyder, 2000), reaching a common agreement on the definition of a community across a particular context is less typical and may be something for RTLB to consider when establishing CoP.

Once a shared understanding of COP is developed, opportunities are created to identify other principles and practices that contribute to effective communities. Much of the literature looks at groups developing a shared vision. While the terms 'vision' and 'purpose' tend to have overlapping messages, the vision intimates where you would like to go and the purpose implies what is happening in the 'now' (Kenny, 2014). With this group of RTLB, knowing why they were meeting appeared to be more important than where they were heading. It seems that designing a purpose gave RTLB clear boundaries regarding their COP and meant they could evaluate whether it was worth investing their time into. There are some considerations regarding this. Too narrow a purpose means that there may be less opportunity to meet individual needs due to an attitude of 'group think' where like-mindedness becomes the guiding force (Dooner et al., 2008). A group with too broad a purpose can become convoluted and confused, as members are not sure of its intent. Considering this in the construction phase of their COP may give RTLB operational boundaries as well as strategic intent (Wenger et al., 2002).

The differences in understanding of what is considered to be 'work-related' also impacts on how COP are valued across the organisational context. The influence of the 'business model' on educational practices, with its focus on visible and viable outcomes, appears to create tension for RTLB. The very essence of COP is to create, expand and exchange knowledge, which requires open-ended and exploratory conversations that involve professional judgement as well as elements of risk-taking and potential failure (Wenger \& Snyder, 2000). Perhaps to enable communities to fulfill their potential, the nature of their journey has to be legitimised and trusted. Recognising the inherent value in the communities themselves, rather than focusing solely on what they produce could do this. Understanding that COP can contribute to deep reflection and promote a more grounded understanding of practice is essential to this process. Also, recognising that building relationships can lead to positive working environments and wider professional networks is another critical understanding.

As noted, the need for autonomy and flexibility were consistently highlighted by the RTLB. These themes have the potential to cause dissonance as they call for compromise between management and RTLB expectations. Wenger and Snyder (2000) suggest that providing an infrastructure to support COP is key. This framework requires setting up organisational systems for communities to develop while still allowing for an openended, flexible approach that is defined by the group in accordance with their needs. Wenger and Snyder (2000) propose the allocation of time and resource, as well as systemic support to grow networks and overcome administrative obstacles. The framework is about facilitation of CoP, rather than leading a group along a particular pathway.

As recognised by the RTLB, 'birthing a community' takes deliberate and concentrated effort. Most literature recognises the importance of mutual trust, openness and safety, and that these ideals are supported by open dialogue and the ability to perspective-take and show respect (Akerson et al., 2009; Bianchini \& Cavazos, 2007; Mak \& Pun, 2015; Mittendorff et al., 2006; Robertson, 2007; Snow-Gerono, 2005). This study confirms these notions and potentially links with Durie's 2006 (cited in Bateman \& Berryman, 2008) themes of 'time, space and boundaries' as an active way of growing whakawhanaungatanga. This could be done by providing time flexibility whereby allocating, expanding or taking time is valued more than fitting with a schedule, enabling space for relationships to grow by clarifying the terms under which parties come together, and exploring boundaries and distinctions between people so that respectful engagement may develop (Bateman \& Berryman, 2008). Added to this could be 'place'; the consideration and freedom to define the place where the COP is held. It may also be beneficial to include some discussion around effective strategies for communication to support this birthing of community.

Strong community does not mean that it will be 'disagreement free' among the members. In this study RLTB noted that there was robust disagreement regarding professional issues. These conversations are invaluable for promoting change in practice and reflect Pane's (2010) ideas regarding the transformative power of uncomfortable conversations and Snow-Gerono's (2005) thoughts on dissensus. Conversations were workrelated rather than personal, and reduced the potential for things to denigrate into bickering or interpersonal conflict. Establishing a sense of mutual respect and ako enables RTLB to have open conversations regarding tensions in their work and this, combined with positive whanaungatanga (relationships), provides a safe place for members to 'hash out' issues in a supportive and professional manner. 


\section{CONCLUSION}

This study has highlighted a number of areas to enhance the effectiveness of Communities of Practice. The artistry in community is about creating and evolving a cohesive body where all members generate a shared understanding of the purpose, intent and definition of CoP. It is from there, through the provision of autonomy and flexibility, that the other principles - engaging the head and the heart, keeping it work-focused, growing whakawhanaungatanga and ako - might grow. The intention is that these COP will result in personal change and have an impact at a wider organisational level.

This study took place inside one RTLB cluster with its own set of protocols and practices. It would be interesting to explore the relevance of these findings across clusters. This inquiry has focused on RTLB beliefs regarding their CoP; it may also be worth examining the dialogue and characteristics of the actual communities and whether the application of these principles has any further impact on their function. Ultimately, this work indicates that with the employment of a few key principles, COP have the potential to allow members to collaboratively approach the difficulties and challenges that are embodied in education, and to provide situated support and innovations to meet those difficulties. This inquiry suggests that COP can contribute to wider learning and change across an organisation.

\section{REFERENCES}

Akerson, V. L., Cullen, T. A., \& Hanson, D. L. (2009). Fostering a community of practice through a professional development program to improve elementary teachers' views of nature of science and teaching practice. Journal of Research in Science Teaching, 46(10), 1090-1113.

Bateman, S., \& Berryman, M. (2008). He hui whakatika: Culturally responsive, self determining interventions for restoring harmony. Kairaranga, 1(9), 6-12.

Bianchini, J. A., \& Cavazos, L. M. (2007). Learning from students, inquiry into practice, and participation in professional communities: Beginning teachers' uneven progress toward equitable science teaching. Journal of Research in Science Teaching, 44(4), 586-612.

Cooperrider, D. (2012). David Cooperrider and associates. Retrieved from http://www.davidcooperrider.com/.

Cooperrider, D., \& Whitney, D. (n.d.). A positive revolution in change: Appreciative inquiry. Draft.

Coppieters, P. (2005). Turning schools into learning organizations. European Journal of Teacher Education, 28(2), 129-139.
Crafton, L., \& Kaiser, E. (2011). The language of collaboration: Dialogue and identity in teacher professional development. Improving Schools, 14(2), 104-116.

Cuddapah, J. L., \& Clayton, C. D. (2011). Using Wenger's communities of practice to explore a new teacher cohort. Journal of Teacher Education, 62(1), 62-75.

Dooner, A.M., Mandzuk, D., \& Clifton, R. A. (2008). Stages of collaboration and the realities of professional learning communities. Teaching and Teacher Education, 24(3), 564-574.

Edwards, F. (2012). Learning communities for curriculum change: Key factors in an educational change process in New Zealand. Professional Development in Education, 38(1), 25-47.

Flores, M. T. (2007). Navigating contradictory communities of practice in learning to teach for social justice. Anthropology \& Education Quarterly, (4), 380.

Fullan, M. (2008). The six secrets of change: What the best leaders do to help their organizations survive and thrive. San Francisco: Jossey-Bass.

Fuller, A., Hodkinson, H., Hodkinson, P., \& Unwin, L. (2005). Learning as peripheral participation in communities of practice: A reassessment of key concepts in workplace learning. British Educational Research Journal, 31(1), 49.

Horn, I. S., \& Little, J. W. (2010). Attending to problems of practice: Routines and resources for professional learning in teachers' workplace interactions. American Educational Research Journal, 47(1), 181-217.

Jenlink, P. M., \& Jenlink, K. E. (2008). Creating democratic learning communities: Transformative work as spatial practice. Collaborative Learning Communities in Schools, 47(4), 311-317.

Kenny, G. (2014). Your company's purpose is not your vision, mission or values. Retrieved from https://hbr. org/2014/09/your-companys-purpose-is-not-its-visionmission-or-values

Louis, K. S. (1994). Beyond "managed change": Rethinking how schools improve. School Effectiveness \& School Improvement, 5(1), 2-24.

Mak, B., \& Pun, S.H. (2015). Cultivating a teacher community of practice for sustainable professional development: Beyond planned efforts. Teachers and Teaching: Theory and Practice, 21(1), 4-21.

McLaughlin, M. W., \& Talbert, J. E. (2006). Building school-based teacher learning communities: Professional strategies to improve student achievement. New York: Teachers College Press.

Menter, I. (2011). A guide to practitioner research in education. London: Sage. 
Ministry of Education (2008). Ka Hikitia: Managing for success - Maori education strategy. Retrieved from https://www.education.govt.nz/assets/Documents/ Ministry/Strategies-and-policies/Ka-Hikitia/ KaHikitia0009PartOne.pdf

Ministry of Education (n.d.). Resource teacher: Learning and behaviour service toolkit. Retrieved from http:// rtlb.tki.org.nz/Professional-practice/RTLB-Practice

Ministry of Education (2015). Resource teacher: Learning and behaviour online. Retrieved from http://rtlb.tki. org.nz/The-RTLB-service/Cluster-lead-school-andareas

Mittendorff, K., Geijsel, F., Hoeve, A., de Laat, M., \& Nieuwenhuis, L. (2006). Communities of practice as stimulating forces for collective learning. Journal of Workplace Learning, 18(5), 298-312.

Pane, D. M. (2010). Viewing classroom discipline as negotiable social interaction: A communities of practice perspective. Teaching and Teacher Education: An International Journal of Research and Studies, 26(1), 87-97.

Pihama, L., Smith, K., Taki, M., \& Lee, J. (2004). A literature review on Kaupapa Maori and Maori education pedagogy. The International Research Institute for Maori and Indigenous Education New Zealand, Auckland: The University of Auckland.

Pink, D. (2009). The puzzle of motivation. Retrieved from http://www.ted.com/talks/dan_pink_on_ motivation?language $=e n$

Printy, S. M. (2008). Leadership for teacher learning: A community of practice perspective. Educational Administration Quarterly, 44(2), 187-226.

Rawlins, P., Ashton, K., Carusi, T., \& Lewis, E. (2014). Investing in educational success: An investigation of the evidence base. Manawatu; Massey University: Institute of Education.

Richmond, G., \& Manokore, V. (2011). Identifying elements critical for functional and sustainable professional learning communities. Science Education, 95(3), 543-570.

Robertson, A. (2007). Development of shared vision: Lessons from a science education community collaborative. Journal of Research in Science Teaching, 44(5), 681-705.

Senge, P. M. (2012). Schools that learn: A fifth discipline fieldbook for educators, parents and everyone who cares about education. New York: Crown Business.

Snow-Gerono, J. L. (2005). Professional development in a culture of inquiry: PDS teachers identify the benefits of professional learning communities. Teaching and Teacher Education, 21, 241-256.
Steenekamp, K., Botha, G., \& Moloi, K. C. (2012). Sustaining change in a learning organization. Africa Education Review, 9(2), 380-394.

Takahashi, S. (2011). Co-constructing efficacy: A "communities of practice" perspective on teachers' efficacy beliefs. Teaching and Teacher Education, 27, 732-741.

Timperley, H. (2007). Teacher professional learning and development: Best evidence synthesis iteration (BES). Wellington, N.Z.: Ministry of Education.

Trotman, D. (2009). Networking for educational change: Concepts, impediments and opportunities for primary school professional learning communities. Professional Development in Education, 35(3), $341-$ 356.

Vescio, V., Ross, D., \& Adams, A. (2008). A review of research on the impact of professional learning communities on teaching practice and student learning. Teaching and Teacher Education, 24, 80-91.

Watson, C. (2014). Effective professional learning communities? The possibilities for teachers as agents of change in schools. British Educational Research Journal, 40(1), 18-29.

Wenger, E. (1999). Communities of practice: Learning, meaning, and identity. Cambridge: Cambridge University Press.

Wenger, E., McDermott, R. A., \& Snyder, W. (2002). Cultivating communities of practice: A guide to managing knowledge. Boston: Harvard Business School Press.

Wenger, E., \& Snyder, W. (2000). Communities of practice: The organizational frontier. Harvard Business Review, (January-February), 139-145.

Wenger, E., \& Trayner, B (n.d.) Introduction to communities of practice. Retrieved from http:// wenger-trayner.com/introduction-to-communities-ofpractice/

Wilson, V., \& Pirrie, A. (2000). Multidisciplinary teamworking indicators of good practice. Spotlights from the Scottish Council for Research in Education, $77,1-4$. 


\section{AUTHOR PROFILES}

$$
\text { Ivanka Soljan }
$$

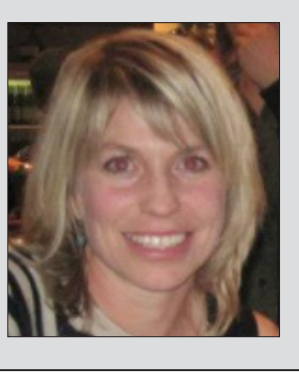

Ivanka Soljan is currently employed as a Resource Teacher: Learning and Behaviour in the Central West Auckland Team and has been involved in the RTLB service for several years. Prior to this, she has spent significant time working in primary and intermediate schools as a classroom teacher and in specialist positions. Along with her commitment to collaborative processes for teachers and RTLB, she also has an interest in socialemotional literacy and how this impacts on students' cognitive processes.

\section{Wendy Holley-Boen}

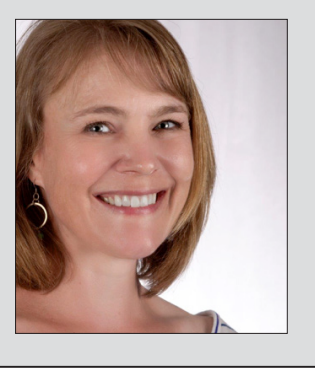

Wendy Holley-Boen is a lecturer at Massey University, and works full-time on the Specialist Teaching Programme. She has been an educational psychologist for twenty years, with interests in strengths-based, ecological practices and equity issues. Wendy is completing a PhD on the fulfilment of specialist teachers and others, which explores their identity, practice and well-being.

Email: W.Holley-Boen@massey.ac.nz

Email: IvankaSljan@cwat.ac.nz 